\title{
Quantification of Tamoxifen Polymeric Nanoparticles in female rodent breast tissue by UPLC/ESI-Q-TOF MS/MS
}

\author{
Md Aftab Alam ${ }^{1}$, Niyaz Ahmad ${ }^{2}$, Rizwan Ahmad ${ }^{3}$, Sushama Talegaonkar ${ }^{4}$, Farhan Jalees Ahmad ${ }^{4}$, Zeenat Iqbal', Amulya K. Panda ${ }^{5}$ \\ 'Department of Pharmaceutics, School of Medical and Allied Sciences, Galgotias University, Gautam Budh Nagar, Greater Noida-201310, INDIA. \\ 2Department of Pharmaceutics, College of Clinical Pharmacy, Dammam University, Dammam- 31441, KINGDOM OF SAUDI ARABIA. \\ ${ }^{3}$ Department of Natural Products and Alternative Medicine, College of Clinical Pharmacy, Dammam University, Dammam-31441, KINGDOM OF SAUDI ARABIA. \\ ${ }^{4}$ Department of Pharmaceutics, Nanomedicine Lab, Faculty of Pharmacy, Jamia Hamdard, Hamdard Nagar, New Delhi-1 10062, INDIA. \\ 5Product Development Cell-II, National Institute of Immunology, New-Delhi-110067, INDIA.
}

\begin{abstract}
Objective: The present work aims to develop and validate stability indicating a novel liquid chromatography method with applicability i.e. to study the pharmacokinetics factor as well as estimate Tamoxifen (TMX) in bio-analytes, using Ultra High Pressure Liquid Chromatography/ Mass Spectrometry (UPLC-ESI-Q-TOF-MS/MS) in plasma. Methods: A bioanalytical method based on UPLC-ESI-Q-TOF-MS/MS has been developed and validated for the quantitative determination of TMX in female mice plasma using Clomiphine as an Internal Standard (IS). After Liquid-liquid extraction (LLE), analyte and IS, chromatographic separation was achieved on ACQUITY UPLC BEH C18 Waters column with dimensions; $100 \mathrm{~mm} \times 2.1 \mathrm{~mm} ; 1.7 \mu \mathrm{m}$, isocratic mobile phase (Acetonitrile:2 $\mathrm{mM}$ ammonium formate: $90: 10 ; \mathrm{v} / \mathrm{v}$ ), and a flow rate of $0.25 \mathrm{~mL} \mathrm{~min}{ }^{-1}$. Results: The transitions occurred at $\mathrm{m} / \mathrm{z}$ $372.1 \rightarrow 178.1$ and $\mathrm{m} / \mathrm{z} 407.1 \rightarrow 100.1$ for TMX and IS, respectively. Liquidliquid extraction technique (LLE) using ethyl acetate was applied in order to optimize the recovery of analytes in mice plasma. The run and retention time of TMX were 6.0 and 2.63 minutes, respectively while the linear dynamic range established was 1.002-4001.07 ng/ml $\left(r^{2}>0.998 \pm 0.0003\right)$. Intra-assay and inter-assay accuracy (\% RSD) was found in the range; 2.43 -
\end{abstract}

3.49. Conclusion: The proposed LC-MS/MS assay method is simple, rapid and sensitive for the determination of TMX in mice plasma for pharmacokinetic studies. Analytes were stable under various conditions i.e. autosampler, freeze-thaw, at room temperature, and under deep freeze conditions.

Key words Tamoxifen, Breast Cancer, UPLC/ESI-Q-TOF-MS/MS method Validation, Polymeric nanoparticles, Pharmacokinetics.

Correspondence :

Dr. Niyaz Ahmad,

Department of Pharmaceutics, College of Clinical Pharmacy, University of Dammam, Dammam, KINGDOM OF SAUDI ARABIA-31441.

P.O. Box 1982, Dammam-31441

Tel: + 966133335541 ,

Cell: + 966 501625406, Fax: + 966133330290

E-mail: nanhussain@uod.edu.sa; niyazpharma@gmail.com

DOI: 10.5530/jyp.2016.4.18

\section{INTRODUCTION}

The chemical name for TMX is Z) -2-[4- (1, 2-Diphenyl-1-butenyl) phenoxyl] -N, N-dimethyl-ethanamine-citrate; 1-p-beta Dimethylamino ethoxy phenyl-trans-1,2-diphenylbut-1-ene citrate (Figure 1). It's a member of class of compounds known as selective estrogen receptor modulators with as estrogen receptor agonist activity in bone, cardiovascular system and endometrium as well as antagonist activity to breast tissues. ${ }^{1,2}$ TMX, a low dose chemotherapeutic agent used since for long time, is considered as the first selective estrogen receptor modulator and the only approved prophylactic drug for healthy women's prone to high breast cancer risks. ${ }^{3}$ TMX, for more than two decades, remained the clinical choice for antiestrogen treatment of various advanced metastatic breast cancers (estrogen receptor ER-positive) i.e. as a first line a non-steroidal antiestrogen regimen for endocrine disorders as well as adjuvant therapy in early and post-menopausal and metastatic breast cancer in animal. Enormous data, mainly based on High Performance liquid chromatography (HPLC), have been reported for quantitative analysis in bulk drug and pharmaceutical formulation ${ }^{4-8}$ i.e. a chiral liquid chromatography tandem mass spectrometric method (LC-MS/MS) for the simultaneous analysis of Plasma samples for Tamoxifen, hydroxy tamoxifen, and dismethyl tamoxifen in $\beta$-cyclodextrin complex of tamoxifen formulation. Similarly, a Waters (liquid chromatography/mass spectrometry/mass spectrometry; LC/MS/MS) system (Milford, MA) was employed for the analyses. ${ }^{9}$ The LC was an Acquity UPLC (Ultra Performance LC) and the triple quadrupole mass spectrometer was a Quadrupole - Time of Flight (Q-TOF). However, UHPLC, a novel chro- matographic technique utilizing high linear velocities, based on concept of using smaller columns have not been utilized till to date.

The purpose of the present work is to develop and validate an assay method indicating stability and have applicability to estimate different sugar based PLGA polymeric nanoparticle formulation of TMX in plasma of female mice alongwith study of pharmacokinetics parameters. An Ultra-Performance Liquid Chromatographic Synapt Mass Spectroscopy (UPLC-MS/MS) ${ }^{9,10}$ method was developed and validated for the quantitative determination of TMX in plasma, using clomiphene citrate as the internal standard (I.S). ${ }^{11}$

\section{MATERIALS AND METHODS}

\section{Standards and chemicals}

Tamoxifen citrate (Assigned purity $>99.5 \%$; M.P. $140-144^{\circ} \mathrm{C}$ ) was obtained ex-gratia from Sanofi Aventis Pharmaceutical Ltd., India. PLGA polymers were purchased from Purac-Biochem, Holland. LCMS grade acetonitrile and methanol were obtained from Sigma Aldrich, (Mumbai, India). Ammonium acetate (LCMS grade), formic acid (LCMS grade), ammonium formate and ethyl acetate were obtained from SD Fine, (Mumbai, India). Formic acid (Assigned purity $>98 \%$ ) was commercially obtained from Fluka analytical, Germany. All Solvents and reagents were analytical grade reagent. Ultra-pure water was produced by a Milli-Q (Millipore, Billerica, MA, USA) system. Eppendorf tubes (1-2 ml) were used to store solution required for the preparation of standard and plasma samples. All the other reagents used were of analytical grade. 


\section{Liquid Chromatography (UHPLC) conditions}

UHPLC analysis of TMX in plasma was performed on a Waters ACQUITY UPLC system (Waters Corp., MA, USA) equipped with a binary solvent delivery system, an auto-sampler, column manager and a tunable synapt MS detector (Synapt; Waters, UK). UPLC Chromatographic separation was performed on a Waters Acquity UPLC BEH $\mathrm{C}_{18}$ column $(100 \times 2.1 \mathrm{~mm}, 1.7 \mu \mathrm{m}$ particle size $)$ with Van Guard pre-column $(5 \times 2.1 \mathrm{~mm}, 1.7 \mu \mathrm{m}$ particle size $)$ Waters Acquity. The mobile phase consisted of Acetonitrile: $2 \mathrm{mM}$ Ammonium Formate buffer:90:10, v/v at column temperature of $40^{\circ} \mathrm{C}$, auto sampler temperature at $4^{\circ} \mathrm{C}$ and flow rate of $0.25 \mathrm{ml} / \mathrm{min}$. The injection volume was $10.0 \mu \mathrm{l}$ in full loop mode. Retention time was $2.63 \mathrm{~min}$ and total chromatographic run time was $6.0 \mathrm{~min}$.

\section{Mass Spectrometry (ESI-Q-TOF-MS/MS) conditions}

Synapt-mass-spectrometric detection was carried out on a UPLC-MS/ MS (Q-TOF-ESI) (Waters Corp., USA) with an electrospray-ionization (ESI) technique. The ESI source was used in positive ionization mode. Quantification was performed using Synapt MS (Q-TOF) of the transitions of $\mathrm{m} / \mathrm{z} 372.1 \rightarrow 178.1$ and $\mathrm{m} / \mathrm{z} 407.1 \rightarrow 100.1$ for TMX and IS respectively, with scan time of $1.0 \mathrm{~min}$ per transition and internal scan time of $0.05 \mathrm{sec}$. Microchannel plate (MCP) was used as a detector plate. The optimized MS parameters are as follows; capillary voltage $3.60 \mathrm{kV}$, cone voltage $21 \mathrm{~V}$, extraction cone voltage $7.40 \mathrm{~V}$, source temperature $120^{\circ} \mathrm{C}$, desolvation temperature, $350^{\circ} \mathrm{C}$, cone gas flow, $50 \mathrm{~L} / \mathrm{h}$; desolvation gas flow of $50 \mathrm{~L} / \mathrm{h}$; and collision energy was 16.5 . Nitrogen was used as the desolvation and cone gas. Argon was used as the collision gas at flow of $1.5 \mathrm{ml} / \mathrm{min}$. All data collected in centroid mode were acquired and processed using Mass Lynx ${ }^{\mathrm{TM}}$ V 4.1 software.

\section{Standard Solutions, Spiked Samples and Quality Control (QC) Sample Preparation}

The standard stock solutions of TMX analyte and clomiphene citrate as an internal standard were prepared at $1000 \mu \mathrm{g} / \mathrm{mL}$ in methanol. It was accompanied with a working solution, containing the adequate concentrations of all the analytes \{prepared in methanol: water (50:50)\} in order to spike the plasma samples covering the linearity range (1.002-4001.07 $\mathrm{ng} / \mathrm{mL}$ ). A $100 \mathrm{ng} / \mathrm{mL}$ solution containing the IS, clomiphene citrate was also prepared in methanol and diluted with methanol: water (50:50). Calibration standard was prepared by spiking a pool of drug free aqueous humour $(50 \mu \mathrm{L}$ for each concentration) with the working standard solution and was diluted to desire concentration range from 1.002 to $4001.07 \mathrm{ng} / \mathrm{ml}$. The final concentration for each analyte was prepared to be $1.002,2.007,44.702,1693.653,2550.682,3400.91$ and $4001.07 \mathrm{ng} / \mathrm{mL}$. Calibration standards were processed according to the sample preparation procedure and analyzed by the UPLC-MS/MS method. QC samples were prepared independently at three levels; $3600.000 \mathrm{ng} / \mathrm{mL}$ (HQC, high quality control), $1600.000 \mathrm{ng} / \mathrm{mL}$ (MQC, middle quality control), and $2.800 \mathrm{ng} / \mathrm{mL}$ (LQC, low quality control) and $1.010 \mathrm{ng} / \mathrm{mL}$ (LLQC).

\section{Sample Treatment}

For, sample preparation, all the solutions (CC standards, QC samples and unknown plasma samples) were freshly prepared prior to perform the experiments. Add $25 \mu \mathrm{L}$ of Clomiphene internal standard approximately $(100 \mathrm{ng} / \mathrm{mL})$ and aliquot $500 \mu \mathrm{L}$ of plasma from the pre-labeled polypropylene cryo-vials into pre-labeled polypropylene tubes, add $200 \mu \mathrm{L}$ aliquot of each samples were taken into glass tube, $50 \mu \mathrm{L}$ of IS $(100 \mathrm{ng} / \mathrm{ml})$ was added in each sample, and further $500 \mu \mathrm{L}$ of formic acid $(5 \% \mathrm{w} / \mathrm{v})$ was incorporated to mixture and vortexes at $300 \mathrm{rpm}$ for $5 \mathrm{~min}$. Finally, plasma extraction of sample using liquid liquid extraction protocol ; in spiked samples add $5 \mathrm{~mL}$ Ethyl Acetate and shacked at reciprocating shaker for $20 \mathrm{~min}$ at $100 \mathrm{rpm}$. Spin the tubes in centrifuge at $4000 \mathrm{rpm}$ for $2-3 \mathrm{~min}$ at $5{ }^{\circ} \mathrm{C}$. Transferred the approximately $4 \mathrm{~mL}$ of supernatant organic layer to clean the glass tubes. Dried under a stream of nitrogen at pressure not more than $20 \mathrm{psi}$ and at a temperature $50 \pm 2.0^{\circ} \mathrm{C}$. Reconstituted the dried elute in $500 \mu \mathrm{l}$ of Mobile Phase. Transferred samples to vials for analysis. Injected the $10 \mu \mathrm{L}$ of the solution into UPLC-MS/MS system for analysis. Processed blank and blank IS samples.

\section{Bioanalytical Method Validation}

The method was validated according to internationally accepted recommendations. ${ }^{12}$ The method was validated in terms of linearity, precision, accuracy, extraction recovery, matrix effect and stability. ${ }^{8-10}$

\section{Specificity}

The selectivity of the method was evaluated by comparing the chromatograms of six different batches of blank aqueous suspension with the corresponding spiked plasma (LLQC samples), to ensure no interfering peak of analyte and I.S. from plasma components.

\section{Linearity and Sensitivity}

The calibration standards of concentrations 1.002, 2.007, 44.702, 1693.653, $2550.682,3400.91$, and $4001.07 \mathrm{ng} / \mathrm{mL}$ were used to assess linearity, which were prepared according to sample preparation. Calibration curves were plotted as the peak area ratio (drug/internal standard) versus the analyte concentration. Least-squares linear regression method was used to determine the slope, intercept and correlation coefficient.

\section{Accuracy and Precision ${ }^{8-10}$}

The precision and accuracy of this analytical method were evaluated by assay QC samples at 4 levels (LOQC, LQC, MQC and HQC). The QC samples were analyzed six times a day to evaluate intra-day precision and accuracy. The same procedure was performed once a day for three consecutive days to determine inter-day precision and accuracy. The accuracy and precision were calculated using the formula published elsewhere and the criteria for acceptability of the data included accuracy within $\pm 15 \%$ standard deviation (SD) from the nominal values and precision within $\pm 15 \%$ relative standard deviation (RSD). ${ }^{13,14}$

\section{Extraction Recovery and Matrix Effect}

The extraction recovery of CRT through the liquid liquid extraction method was evaluated at four QC concentrations: 2.800 (LQC), 1600.000 (MQC) and 3600.000 (HQC) $\mathrm{ng} / \mathrm{mL}(\mathrm{n}=6)$. Extraction recovery was determined by comparing the peak areas obtained from blank plasma spiked with analyte before the extraction with those from samples to which analyte were added after the extraction. The matrix effect was assayed by post extraction spike method to compare the peak areas (A) of blank plasma spiked with analyte known concentration (MQC) was compared with corresponding peak area (B) obtained by direct injection of standard in the mobile phase. The ratio $(\mathrm{A} / \mathrm{B} \times 100)$ is defined as matrix effect.

\section{Ex vivo Stability Assessment}

The stability of TMX in rodent plasma was evaluated by analyzing six replicates of plasma samples at the concentrations of $2.8 \mathrm{ng} / \mathrm{ml}$ (LQC) and $3600 \mathrm{ng} / \mathrm{ml}$ (HQC) which were exposed to different conditions (time and temperature). Percentage stability was determined as; $\%$ Stability $=$ mean corrected response of stability stock / mean response of comparison stock x 100 . 


\section{Long Term Stability}

The long-term stability was assessed after storage of the standard spiked plasma samples at deep freeze $\left(80^{\circ} \mathrm{C}\right)$ for one month. Six replicates of LQC and HQC were used for analysis.

\section{Freeze Thaw Stability}

The freeze/thaw stability in plasma was evaluated for three consecutive freeze-thaw cycles from $20^{\circ} \mathrm{C}$ to room temperature $\left(+25^{\circ} \mathrm{C}\right)$. Six replicates of LQC and HQC were analyzed after undergoing three freezethaw cycles.

\section{Bench Top Stability}

Bench top stability was determined for $24 \mathrm{~h}$ storage in time dependent conditions, using six sets each of LQC and HQC. The QC samples were quantified against the freshly spiked calibration curve standards.

\section{Post Processing Stability}

Short-term stability was determined after the exposure (of processed samples) at $10^{\circ} \mathrm{C}$ for $24 \mathrm{hr}$ in auto-sampler using six sets each of LQC and HQC. After specified storage conditions, samples were processed and analyzed. The analytes are considered to be stable when the precisions are below $15 \%$ and the accuracies are in the range of $85-115 \%$ respectively for both levels. ${ }^{15}$

$$
\text { Stability }(\%)=\frac{\text { Mean corrected response of stability stock }}{\text { Mean response of comparison stock }} \times 100
$$

\section{Preparation and Characterization of TMX Nanoparticles}

PLGA polymeric nanoparticles were prepared using o/w single emulsion solvent evaporation method. ${ }^{11}$ Briefly, an emulsion between organic phase (OP) containing TMX drug (5 mg/ml) and PLGA polymer $(50 \mathrm{mg} / \mathrm{mL}$ PLGA solution in dichloromethane; DCM) was prepared by sonication (20 W, 40\% duty cycle for $1 \mathrm{~min}$ ) (Bandlein Sonifier, D-12207, USA) and the resulting emulsion was formed by adding drop wise organic OP to external aqueous phase (EAP) containing 1\% (w/v) PVA and $10 \%(\mathrm{w} / \mathrm{v})$ of sugars i.e. in MQ water. The resulting o/w emulsion was kept overnight under magnetic stirring for DCM removal. Nanoparticles were collected by centrifugation (15,000 rpm, $30 \mathrm{~min})$, washed 3 times with Milli-Q water, finally resuspended in $4 \mathrm{~mL}$ of Milli-Q water and dried in a lyophilizer (Heto Drywinner, Germany).

\section{Characterization of Polymeric Nanoparticles}

Nanoparticles were characterized for particle size distribution microscopy image. For SEM analysis (SEM, Zeiss Instrument), a drop of sugar based nasnosuspension was mounted on aluminium stub with the help of black carbon tape and air dried at room temperature. Next, the samples were placed in vacuum chamber of SEM gold coating apparatus and gold was coated at $2.5 \mathrm{kv}, 25-30 \mathrm{~mA}$ for $180 \mathrm{sec}$. The morphology of the particles using SEM (Figure 2) at $25.0 \mathrm{KV}$, nominal magnification of 13,00040,000 and scan speed $=8$ were observed.

\section{In Vivo Pharmacokinetic Study Experimental Animal}

Swiss Albino Female Mice ( $\mathrm{n}=6$; 25-35 g, 8-10 weeks old) were provided from Experimental Central Animal House, Hamdard University and kept in an environmentally controlled room (Temperature: $25 \pm 2^{\circ} \mathrm{C}$, humidity: $60 \pm 5 \%, 12 \mathrm{hr}$ dark-light cycle) for at least 1 week before the experiments. Animals were fed on standard pelleted diet (Ashirwad Industries, Chandigarh, India) and water was provided ad libitum. The mice were fasted overnight before the day of the experiment.

\section{Experimental Design Protocol}

The animal protocol used in this study was approved by Hamdard University's Institutional Animal Ethics Committee. Mice were fasted for $12 \mathrm{hr}$ with free access to water prior to the pharmacokinetic investigation. The bioanalytical method was implicated for quantitative estimation of TMX in mice plasma after a single intravenous dose $(5 \mathrm{mg} / \mathrm{kg}$ dissolved in distilled water). From retero-orbital complex of eye, $200-400 \mu \mathrm{L}$ of blood samples were withdrawn and procured in pre-heparinized glass tubes at different time intervals $(0.083,0.5,1,2,4,6,12,24$ and $48 \mathrm{hr})$. Further, blood samples were centrifuged $\left(2500 \mathrm{x}\right.$ g; $\left.10 \mathrm{~min} ; 20^{\circ} \mathrm{C}\right)$ to separate plasma fractions. The collected plasma samples were preserved for investigation at $80^{\circ} \mathrm{C}$ until analysis. Concentration time curves were established for each analyte and used for the determination of pharmacokinetic parameters such as peak plasma concentration $\left(\mathrm{C}_{\max }\right)$, extent of absorption (AUC) using linear trapezoidal method and half-life $\left(\mathrm{t}_{1 / 2}\right)$, by a non-compartmental analysis using PK Solutions Version 2.0; Summit Research Services, USA.

\section{RESULTS AND DISCUSSION}

\section{Optimization of UPLC/MS/MS Method}

TMX is a low molecular weight compound (MW; 563.64), containing a secondary amine in its structure. Due to the presence of basic nitrogen in the molecule, TMX exhibited good sensitivity in positive ion mode detection. Optimum chromatographic separation of TMX, was achieved by Acetonitrile: Ammonium Formate buffer (90:10; v/v), with a flow rate of $0.25 \mathrm{~mL} / \mathrm{min}$. Baseline separation of both TMX and IS was obtained within runtime of $6 \mathrm{~min}$, without any interference. Methanol, acetone and isopropyl alcohol have been also tried for mobile phase selection but they didn't afford chromatographic separation. Although various buffer systems were studied but the fine peak with better signal response was observed for $2 \mathrm{mM}$ ammonium formate buffer, due to its volatile and compatible nature. The MS full scan spectra for TMX showed protonated precursor $[\mathrm{M}+\mathrm{H}]^{+}$ions at $\mathrm{m} / \mathrm{z} 372.1$ and product ion mass spectra at m/z 178.05 respectively (Figure 3A \& 3B). During direct infusion, the mass spectra of IS showed precursor ion peaks at $\mathrm{m} / \mathrm{z} 407.1$ as $[\mathrm{M}+\mathrm{H}]^{+}$ions and most abundant product ions at $\mathrm{m} / \mathrm{z} 100.1$ (Figure 4A \& 4B). The optimum collision energies employed were $33.0 \mathrm{eV}$ for both TMX and IS, respectively. Quantification was done on the basis of main product ions. Identical capillary voltage of $2.95 \mathrm{KV}$ was used for monitoring the precursor ions. The most widely employed biological sample preparation methodologies currently are liquid-liquid extraction (LLE), protein precipitation (PPT), and solidphase extraction (SPE). In the early stage of method development, a PPT method was employed to separate TMX from plasma samples, but strong ion suppression from the endogenous substances in plasma occurred (at $1 \mathrm{~min}$ ). Although it could be decreased by chromatographic separation, the run time would be sacrificed. Finally, liquid-liquid extraction (LLE) procedures were used to prepare TMX plasma samples in our study. To obtain optimum recovery, four organic extraction solvents were evaluated including ethyl ether, ethyl acetate, ethyl ether-dichloro-methane $(2: 1 ; \mathrm{v} / \mathrm{v})$ and $\mathrm{n}$-hexane dichloro-methane $(2: 1 ; \mathrm{v} / \mathrm{v})$. It was found that ethyl acetate alone could yield the highest recovery (>80\%) for TMX and IS. However, we used Waters ACQUITY UPLC $^{\mathrm{TM}}$ BEH C18 column with $1.7 \mu \mathrm{m}$ particle size which helped in separation and elution of both analytes, Extracted Plasma Peak of Tamoxifen with LLOQ, Standard B and IS at $2.63( \pm 0.05), 2.63( \pm$ $0.05)$ and $2.55( \pm 0.06) \mathrm{min}$, respectively (Figure 5B, 5C, and 5D). Chromatogram of blank plasma (extracted and reconstituted) is shown (Figure 5A); however TMX extracted spiked plasma sample has shown in (Figure 5C). 

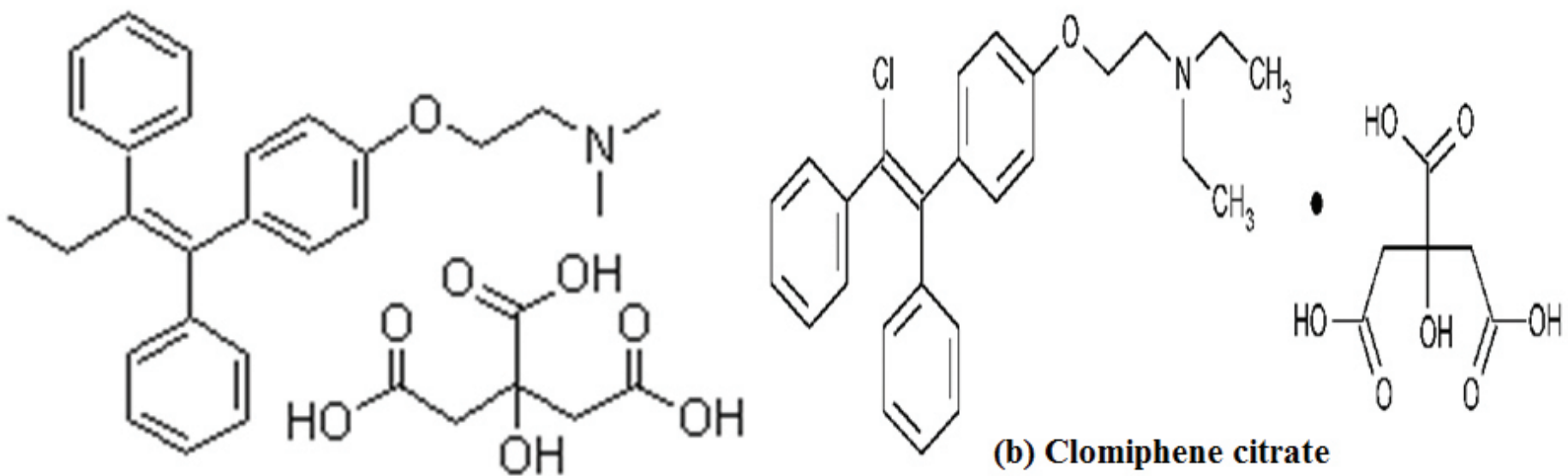

(a) Tamoxifen citrate

(b) Clomiphene citrate

Figure 1: Chemical structure of (a) Tamoxifen citrate (Drug) (b) Clomiphene citrate (IS: Internal standard).

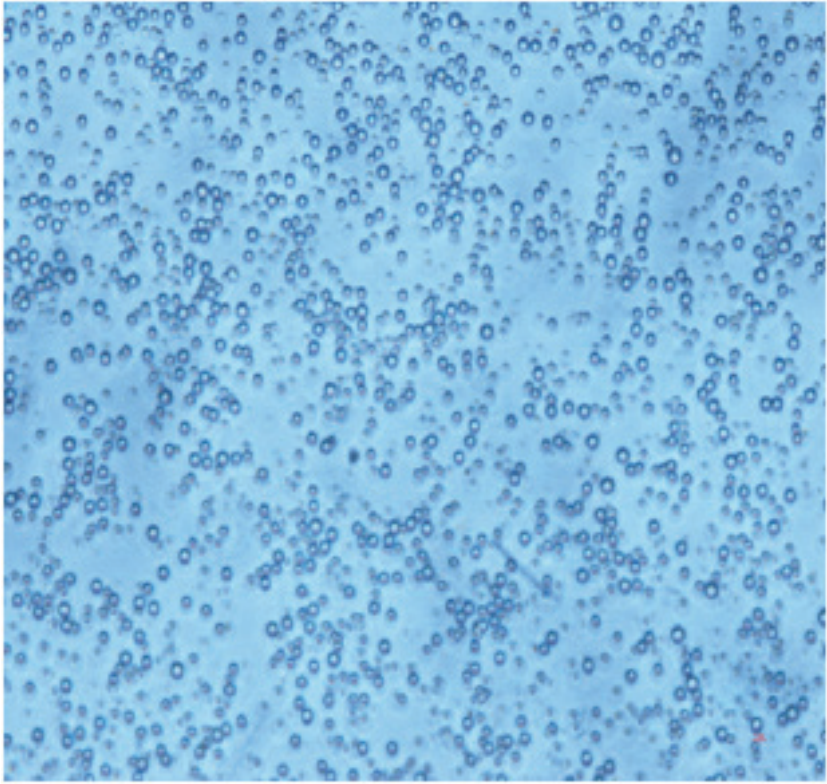

(a) TEM

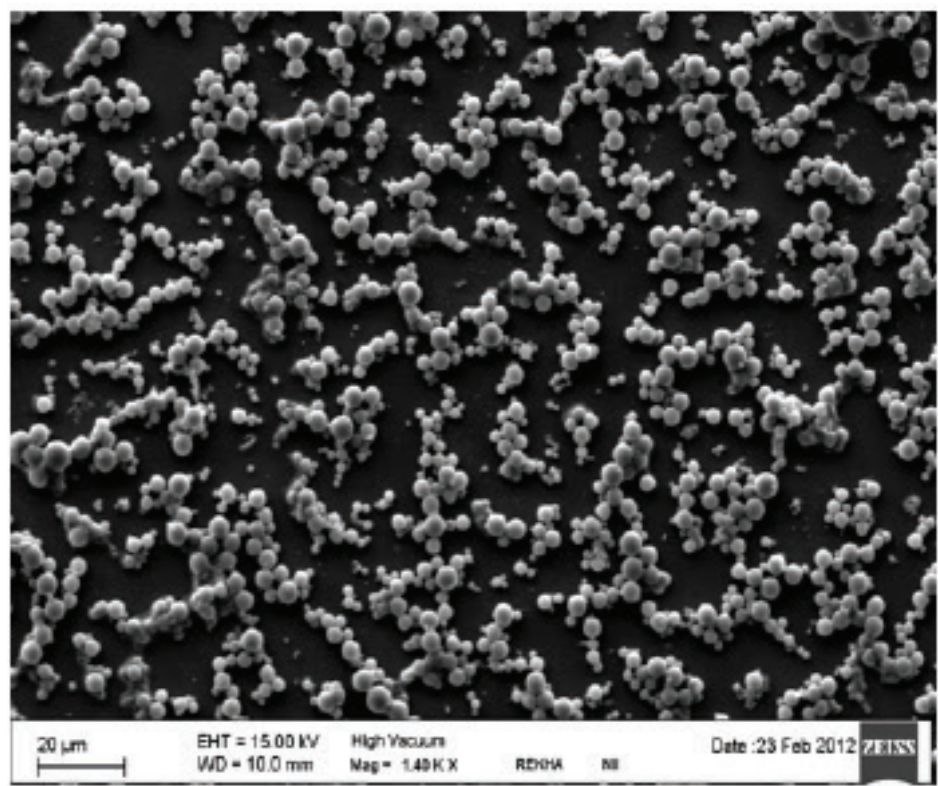

(b) SEM

Figure 2: Images: (A) Microscopy image (B). SEM images of mannitol based nanoparticle formulation. 

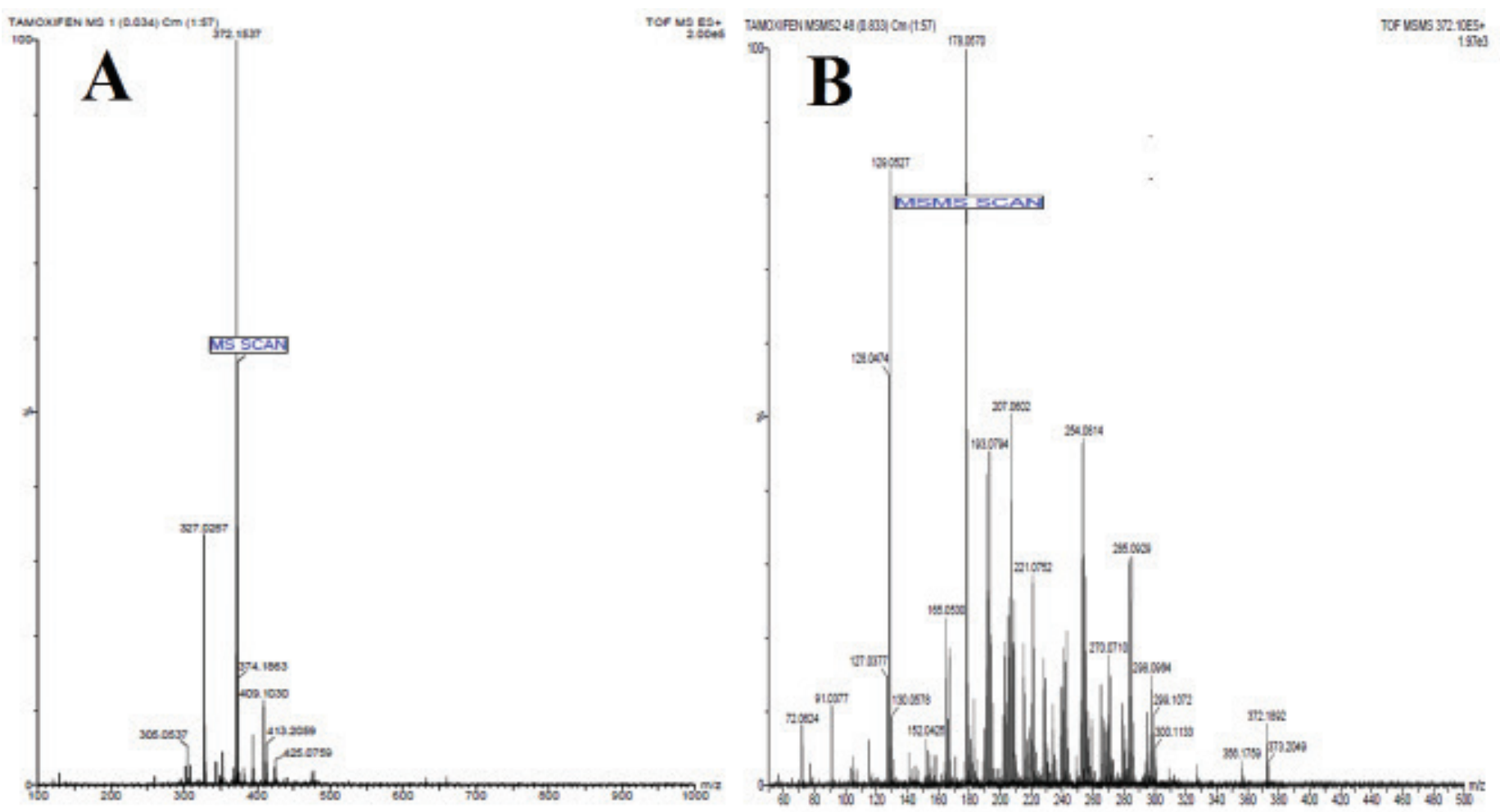

Figure 3: Mass spectrum of (A) Tamoxifen parent ion (major precursor $[\mathrm{M}-\mathrm{H}]^{+}$ions at $\mathrm{m} / \mathrm{z} 372.1$ ) and (B) Tamoxifen product ion (major fragmented product ion at $\mathrm{m} / \mathrm{z} 178.05$ ) showing fragmentation transitions.
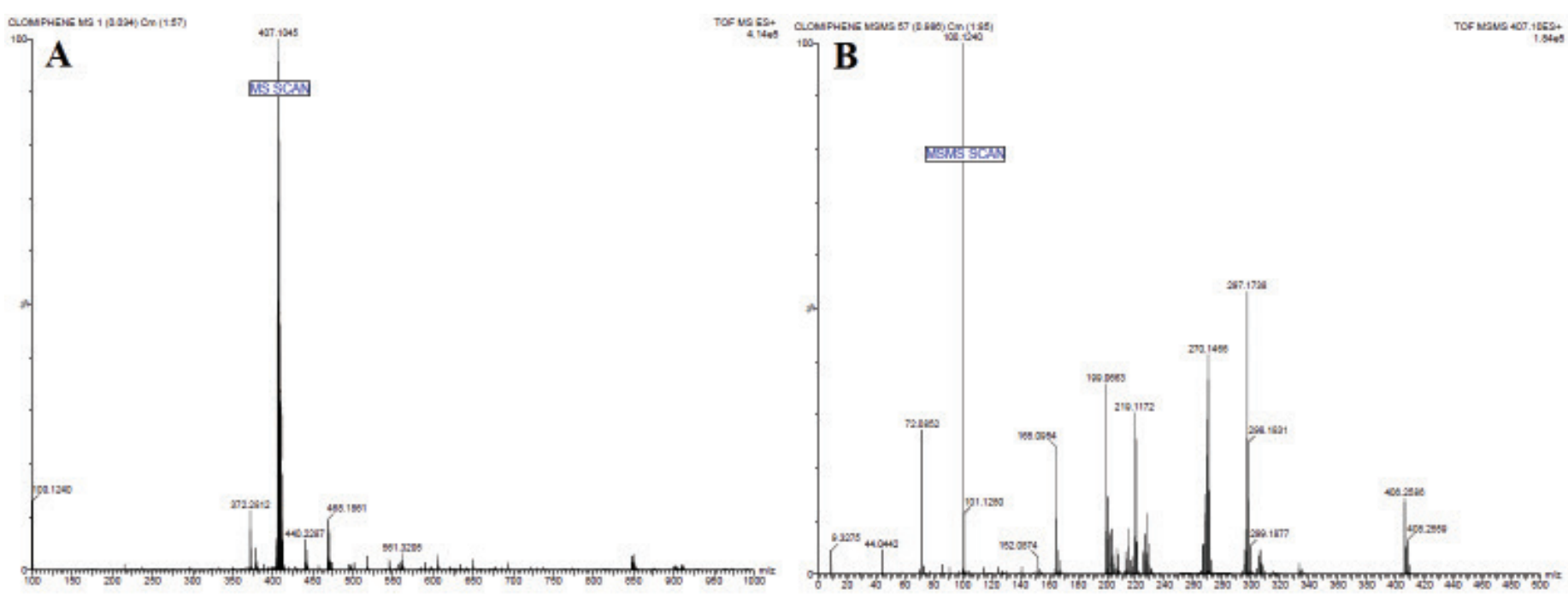

Figure 4: Mass spectrum of (A) Clomiphene parent ion (major precursor $[\mathrm{M}-\mathrm{H}]^{+}$ions at $\mathrm{m} / \mathrm{z} 407.1$ ) and (B) Clomiphene product ion (major fragmented product ion at $\mathrm{m} / \mathrm{z}$ 100.1) showing fragmentation transitions. 

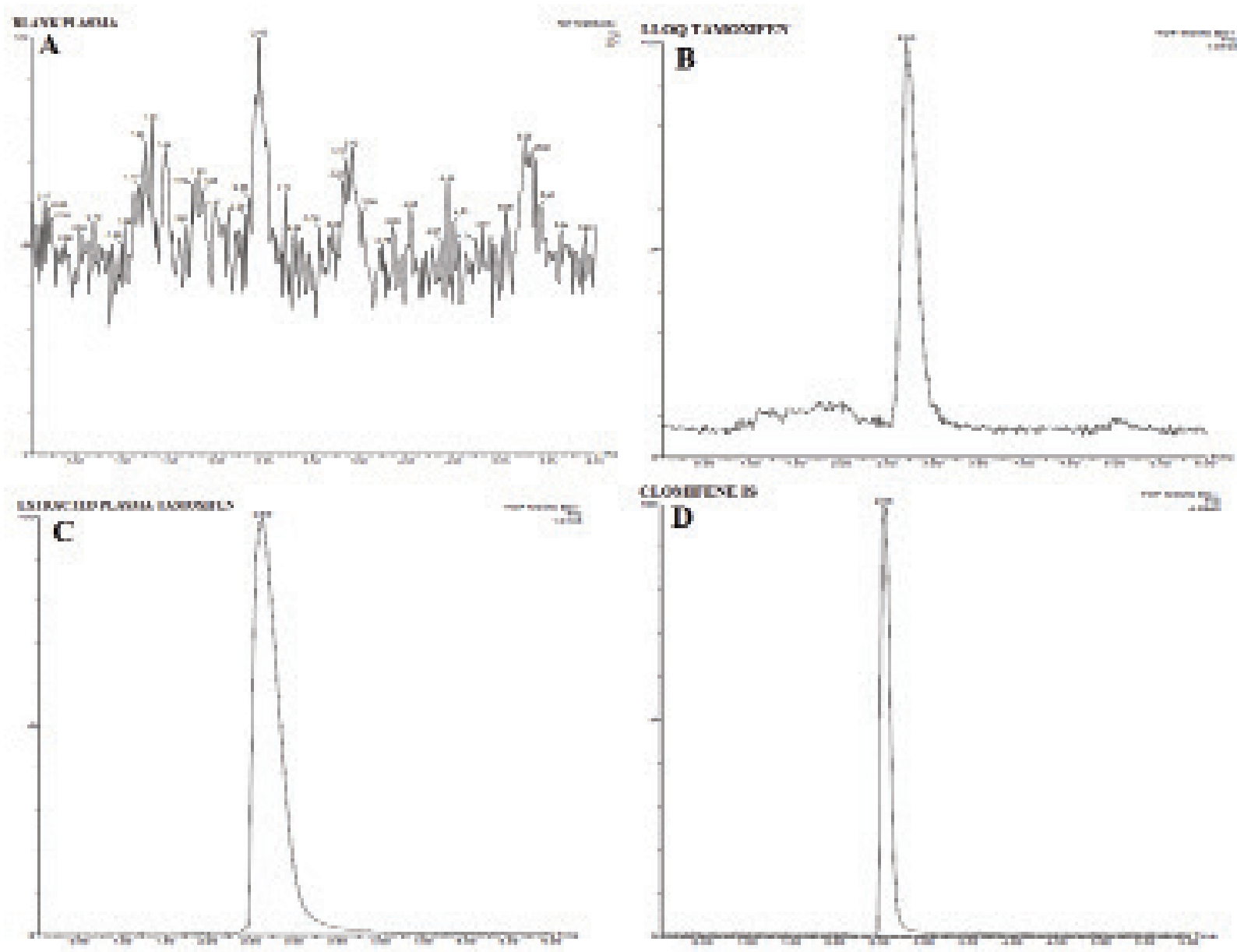

Figure 5: Typical chromatograms of (A) Blank Plasma Extracted, (B) LLOQ Plasma spike Extracted Tamoxifen, (C) Extracted Plasma Tamoxifen, (D) Plasma Extracted Clomiphene IS extracted after spiking with Female mice by selective reaction monitoring scan mode.

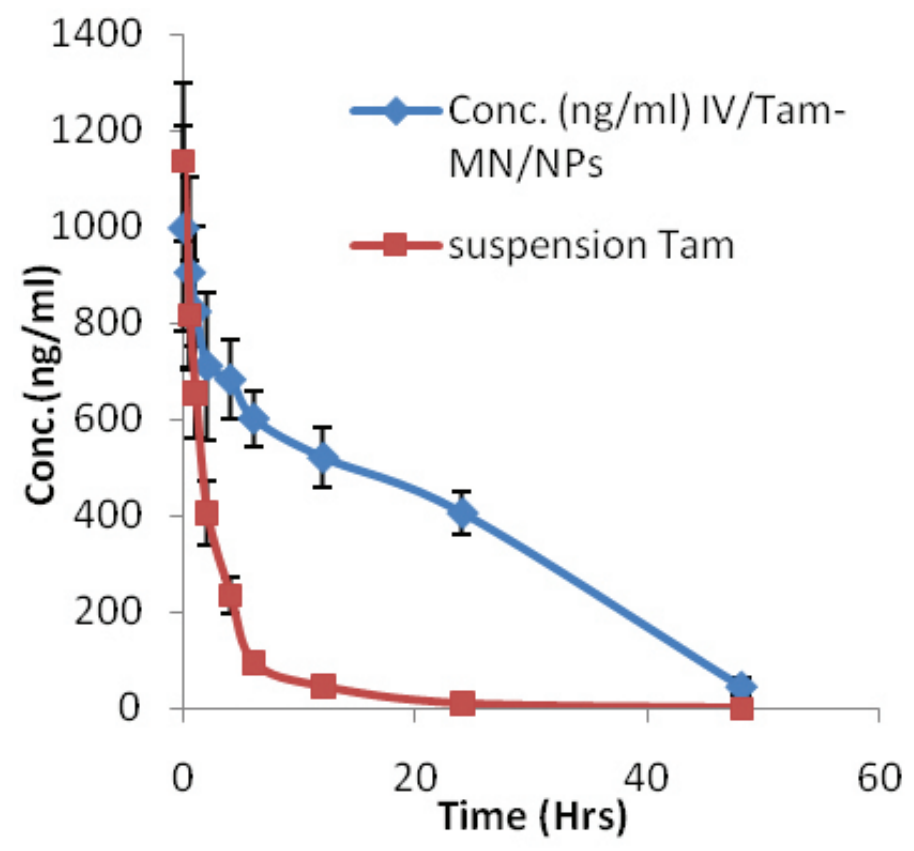

Figure 6: Plasma conc. vs. time curve of Tamoxifen (10 mg/kg, IV) in Albino mice. Each time point is mean $\pm S D(n=6)$. 
Table 1: Precision and Accuracy of Drug in Plasma $(n=6)$

\begin{tabular}{|c|c|c|c|c|c|c|}
\hline \multirow[b]{2}{*}{ Conc (ng/ml) } & \multicolumn{3}{|c|}{ Intra- day } & \multicolumn{3}{|c|}{ Inter day } \\
\hline & $\begin{array}{l}\text { Measured conc. } \\
\text { (Mean } \pm \text { SD) } \\
\text { (ng/mL) }\end{array}$ & $\begin{array}{l}\text { Precision } \\
\text { (RSD, \%) }\end{array}$ & $\begin{array}{c}\text { Accuracy } \\
\text { (Mean } \pm \text { SD, \%) }\end{array}$ & $\begin{array}{c}\text { Measured Conc. } \\
(\text { Mean } \pm \text { SD) }(\mathrm{ng} / \mathrm{mL})\end{array}$ & $\begin{array}{l}\text { Precision } \\
\text { (\% RSD) }\end{array}$ & $\begin{array}{c}\text { Accuracy } \\
(\text { Mean } \pm \text { SD, \%) }\end{array}$ \\
\hline 2.8 (LQC) & $2.76(0.12)$ & 4.34 & $98.57(2.25)$ & $2.78(0.11)$ & 3.36 & $99.20(3.05)$ \\
\hline 1600 (MQC) & $1597.50(15.82)$ & 0.97 & $99.84(2.69)$ & $1595.26(18.54)$ & 1.16 & $99.70(2.43)$ \\
\hline 3600 (HQC) & $3594.23(37.71)$ & 1.094 & $99.83(3.12)$ & $3596.94(41.08)$ & 1.14 & $99.91(3.49)$ \\
\hline
\end{tabular}

RSD (\%): relative standard deviation.

Table 2: Extraction Recovery and Matrix Effect $(n=6)$

\begin{tabular}{cccc}
\hline Conc. (ng/mL) & $\begin{array}{c}\text { Recovery } \\
\text { (Mean } \pm \text { SD) (\%) }\end{array}$ & $\begin{array}{c}\text { Matrix effect } \\
\text { (Mean } \pm \text { SD) }(\%)\end{array}$ & \% RSD \\
\hline $2.8(\mathrm{LQC})$ & $93.43(5.43)$ & $96.34(3.23)$ & 3.35 \\
$1600(\mathrm{MQC}$ & $96.90(2.92)$ & $98.72(2.12)$ & 2.14 \\
$3600(\mathrm{HQC})$ & $97.32(3.23)$ & $97.54(2.45)$ & 2.51 \\
\hline
\end{tabular}

Table 3: Summary of Stability Assessment ( $n=6)$

\begin{tabular}{|c|c|c|c|c|}
\hline Conc. (ng/ml) & Stability & Mean \pm SD $(\mathrm{ng} / \mathrm{ml})$ & Drug Remaining (\%) & RSD (\%) \\
\hline \multirow{4}{*}{$\begin{array}{c}\text { LQC } \\
(2.8 \mathrm{ng} / \mathrm{mL})\end{array}$} & Initial (0 hr) & $2.82(0.02)$ & 100 & 071 \\
\hline & Short-term stability $\left(25^{\circ} \mathrm{C}, 24 \mathrm{hr}\right)$ & $2.80(0.04)$ & 99.29 & 1.42 \\
\hline & Long-term stability $\left(-80^{\circ} \mathrm{C}, 1\right.$ month) & $2.76(0.03)$ & 98.57 & 1.09 \\
\hline & $\begin{array}{l}\text { Three cycles freeze-thaw stability } \\
\text { (three cycles, }-20^{\circ} \mathrm{C} \text { to } 25^{\circ} \mathrm{C} \text { ) }\end{array}$ & $2.78(0.04)$ & 99.64 & 1.44 \\
\hline \multirow{6}{*}{$\begin{array}{c}\text { HQC } \\
(3600 \mathrm{ng} / \mathrm{mL})\end{array}$} & Post-preparative stability $\left(10^{\circ} \mathrm{C}, 24 \mathrm{hr}\right)$ & $2.79(0.02)$ & 98.94 & 0.72 \\
\hline & Initial (0 hr) & $3595.49(18.71)$ & 100 & 0.52 \\
\hline & Short-term stability $\left(25^{\circ} \mathrm{C}, 24 \mathrm{hr}\right)$ & $3585.87(28.54)$ & 99.73 & 0.80 \\
\hline & Long-term stability $\left(-80^{\circ} \mathrm{C}, 1\right.$ month) & $3578.54(38.32)$ & 99.52 & 1.07 \\
\hline & $\begin{array}{l}\text { Three cycles freeze-thaw stability } \\
\text { (three cycles, }-20^{\circ} \mathrm{C} \text { to } 25^{\circ} \mathrm{C} \text { ) }\end{array}$ & $3566.45(25.26)$ & 99.19 & 0.71 \\
\hline & Post-preparative stability $\left(10^{\circ} \mathrm{C}, 24 \mathrm{hr}\right)$ & $3560.74(17.43)$ & 99.03 & 0.49 \\
\hline
\end{tabular}

Table 4: Pharmacokinetic Parameter of Drug Suspension and DrugNanoparticle Formulation

\begin{tabular}{ccc}
\hline Pharmacokinetic parameter & TMX- Suspension & TMX-MNP \\
\hline $\mathrm{C}_{\max }(\mathrm{ng} / \mathrm{mL})$ & $1135(23.24)$ & $996(116.21)$ \\
$\mathrm{t}_{1 / 2}(24 \mathrm{hr})$ & $1.86(0.09)$ & $20.49(1.5)$ \\
$\mathrm{t}_{1 / 2}(48 \mathrm{hr})$ & $\mathrm{NA}$ & $11.92(1.8)$ \\
Elimination half-life $(24 \mathrm{hr})$ & $0.371(0.004)$ & $0.033(0.007)$ \\
Elimination t $_{1 / 2}(48 \mathrm{hr})$ & $\mathrm{NA}$ & $0.058(0.049)$ \\
$\mathrm{AUC}_{0-24}(\mathrm{ng} / \mathrm{mL} . \mathrm{h})$ & $3251.92(45.1)$ & $13223.73(149.4)$ \\
$\mathrm{AUC}_{0-48}(\mathrm{ng} / \mathrm{mL} . \mathrm{h})$ & $\mathrm{NA}$ & $18611.73(137.2)$ \\
\hline
\end{tabular}




\section{Validation of the Bioanalytical Method Specificity}

The selectivity was evaluated by comparing the chromatograms of plasma, and spiked plasma (LLOQ, $1.01 \mathrm{ng} / \mathrm{mL}$ ) in pharmacokinetic studies. Comparison of spiked plasma samples and blank plasma showed no significant peaks interfering with the quantification of the analyte and I.S. and the representative chromatogram of real plasma samples showed similar chromatographic behavior to QCs.

\section{Linearity and Sensitivity}

The calibration curve was linear with regression correlation coefficients $\left(r^{2}=0.999\right.$ over the concentration range of $1.002-4001.07 \mathrm{ng} / \mathrm{mL}$. The regression coefficient of the calibration curves was: $r^{2}=0.998$. The limit of quantification (LOQ) was found to be $2.8 \mathrm{ng} / \mathrm{mL}$ in plasma $(\geq 10)$, which was sufficient to support pharmacokinetic studies of TMX. The accuracy of the diluted samples of CRT was $98.57 \pm 2.25 \%$ at $2.8 \mathrm{ng} / \mathrm{mL}$ and $99.83 \pm$ $3.12 \%$ at $3600 \mathrm{ng} / \mathrm{mL}$. The precision determined at each concentration level was within $5 \%$ of the relative standard deviation (\%R.S.D.). The LOD and LOQ were determined as 2.8 and $3600 \mathrm{ng} / \mathrm{mL}$ respectively for TMX in plasma. Dilution study found that the assay was reasonable to quantify TMX in samples that exceeded the upper limit by an appropriate dilution.

\section{Precision and Accuracy}

The intra-day and inter-day precision and accuracy for the tested concentrations (LLQC, LQC, MQC, MQC and HQC) were within acceptable limits as shown in Table1. Intra-day precision (expressed as percent relative standard deviation, \%R.S.D.) ranged from 1.094 to $3.34 \%$ and the inter-day precision ranged from 1.14 to $3.36 \%$. The precision values were found to be within the accepted limits, which indicated that the method was reproducible. Intra and inter-day accuracy ranged from $98.57 \pm 2.25$ to $99.83 \pm 3.12 \%$ and $96.04 \pm 0.99$ to $99.20 \pm 3.05 \pm 3.49 \%$, respectively, and found to be within the accepted limits. This indicated that the method was accurate and reliable.

\section{Extraction Recovery and Matrix Effect}

Extraction recovery and matrix effect were determined as described in earlier section and the data is shown in Table 2. The extraction recovery of the compound from TMX matrix was $93.43 \pm 5.43$ to $97.32 \pm 3.23 \%$ at LQC, MQC and HQC concentrations. As for ionization, the peak areas of CRT after spiking evaporated aqueous humour samples at four (LQC, MQC, MQC and HQC concentrations) concentration levels were comparable to neat standard solutions (ranged from $96.34 \pm 3.23 \%$ to $98.72 \pm 2.12 \%$ ), suggesting that there was no measurable matrix effect interfered with TMX determination in plasma sample.

\section{Ex vivo Stability Study}

The Stability of plasma sample was done at different storage condition such as short term, long-term, freeze- thaw, and post processing stability. The result of this stability was found to be that CRT was stable during all storage conditions and results of stability experiments are presented in Table 3. The analytes stability study in plasma sample was investigated at two QC levels i.e. LQC and HQC. The recovery of the analytes relative to that at time zero was reviewed. After short term for $24 \mathrm{~h}$ storage the recovery of TMX was $99.29 \%$ at LQC and $99.7 \%$ at HQC. After 1 month of storage (Long-term stability) the recovery of TMX was $98.57 \%$ at LQC, and 99.52\% HQC. After 1, 2 and 3 cycles of freeze-thaw (freezethaw stability), the average recovery of T was $99.64 \%$ at LQC and $99.19 \%$ at HQC. The recovery (post processing stability) of CRT was $98.94 \%$ at LQC and $99.03 \%$ (HQC). The above results showed that a sensitive, reproducible, and robust method for the analysis of TMX in plasma had been developed and validated.

\section{Preparation and Characterization of CRT Nanoparticles}

TMX loaded polymeric nanoparticles was prepared by solvent evaporation method using lyophillization technique. The nanoparticles were characterized as particle size, zeta potential, PDI, assay of the drug and morphology by TEM. The particle size optimize formulation were $274.33 \pm$ $5.66 \mathrm{~nm}$. The morphology of nanoparticles was smooth and spherical in shape (Figure 2).

\section{Pharmacokinetic Study}

The validated UPLC-MS/MS analytical method was successfully used to quantify plasma concentrations of TMX from TMX solution and TMX polymeric mannitol based nanoparticles in the pharmacokinetic study in female mice. The high sensitivity of the present method our assay allowed to measure plasma concentrations up to $48 \mathrm{hr}$ post dosing. The formulations (TMX-suspension and TMX-nanoparticles, dose $10 \mathrm{mg} /$ $\mathrm{kg}$ of body weight) were injected through tail vein and the developed UPLC-MS/MS method was applied to determine their in vivo pharmacokinetics at predetermined time intervals. Figure 5, shows the plasma concentration-time profiles of Tamoxifen citrate drug (API) and optimized mannitol based TMX-NPs, after dosing. The pharmacokinetic parameters in plasma such as $\mathrm{AUC}_{0-\mathrm{t}}, \mathrm{AUC}_{0-\infty}, \mathrm{C}_{\max }$, and $\mathrm{t}_{1 / 2}$ obtained from the pooled concentration- time, data are shown in Table 4 . In contrast, in the group treated with TMX the drug was detected in plasma for $48 \mathrm{hr}$ $\left(3251.92 \pm 45.1 \mathrm{ng} / \mathrm{mL}\right.$ ) (Figure 6). The increased $t_{1 / 2}$ value of TMX-NPs $(20.49 \pm 1.5 \mathrm{~h})$ indicated its sustained release ability. The $\mathrm{AUC}_{0-\mathrm{t}}$ applied by TMX- NPs formulation (AUC : $_{0 . t} 13223.73 \pm 149.4 \mathrm{ng} / \mathrm{mL}$. h) was 4.06 times higher, compared with to TMX-solution $\left(\mathrm{AUC}_{0-\mathrm{t}} 3251.92 \pm 45.1\right.$ $\mathrm{ng} / \mathrm{mL}$. It could also be seen that maximum level $\left(\mathrm{C}_{\max }\right)$ of TMX in plasma of TMX -nanoparticles was approximately 1.13 fold $(1135 \pm 23.24$ $\mathrm{ng} / \mathrm{mL}$ ) higher than to TMX-Solution $(996 \pm 116.21 \mathrm{ng} / \mathrm{mL}$ ) (Figure 6). It is due the size range $(274.33 \pm 5.66 \mathrm{~nm})$ of polymeric nanoparticles; interact with blood plasma and prolonged circulation time. ${ }^{14-16}$ The results also indicated that the polymeric nanoparticles are able to deliver optimum levels of drug into plasma and show promise for chemopreventive drug delivery for management of breast tumor.

\section{CONCLUSION}

This work describes the development, validation and application of a UPLC-MS/MS method for the quantitative analysis of TMX suspension and optimized mannitol based nanoparticles in plasma samples. In addition to this the method developed would be a stability indicating method. The TMX is extracted by a simple and fast liquid-liquid extraction method. The relatively simple sample preparation together with the short run time (2.57 $\mathrm{min}$ ) makes the present method more practical for high throughput sample analysis. The method was proven to be highly sensitive, accurate and selective, making it suitable for high-throughput quantitative analysis of TMX. The LOQ for analysis of TMX can be modified to $2.8 \mathrm{ng} / \mathrm{mL}$ if greater sensitivity is needed. The assay was successfully employed for pharmacokinetic studies in female mice plasma with acceptable precision, adequate sensitivity and satisfied accuracy. It would be, furthermore, applicable for further human trials studies.

\section{ACKNOWLEDGMENTS}

The authors are thankful to Indian Council of Medical Research (India), for providing Senior Research Fellowship (File No. 45/45/2009/PHA$\mathrm{BMS}$ ) as a financial help to conduct this project. We are also grateful to Sanofi Aventis for providing a gift sample of pure drug. 


\section{ABBREVIATIONS USED}

LC-MS/MS: Liquid Chromatography/Mass Spectrometry, US FDA: United States Food and Drug Administration, HPLC: High Performance Liquid Chromatography, PP: Protein Precipitation, IS: Internal Standard, LLE: Liquid-liquid Extraction, SPE: Solid-Phase Extraction, CE: Collision Energy, EP: Entrance Potential, CXP: Collision Cell Exit Potential, LLOQ: Lower Limit of Quantitation, ULOQ: Upper Limit of Quantitation, LLOQ OC: Lower Limit of Quantitation Quality Control, LQC: Low Quality Control, MOC: Medium Quality Control, HOC: High Quality Control, EDTA: Ethylene Diamine tetra acetic acid, ESI: Electro Spray Ionization, TMX: Tamoxifen, TMXC: Tamoxifen citrate.

\section{ABOUT AUTHOR}

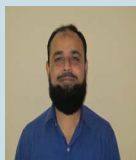

Niyaz Ahmad: Obtained his Ph. D. degree in 2015 from Department of Pharmaceutics, Faculty of Pharmacy, Jamia Hamdard, New Delhi, India. Currently, he is positioned as Assistant Professor at the Department of Pharmaceutics, College of Clinical Pharmacy, University of Dammam, Dammam, Saudi Arabia. He is member of Research and Strategic Planning committee of Clinical Pharmacy, University of Dammam since 2013. Dr. Niyaz has so far published more than 35 papers in national and international journals and conferences. He has attended many international conferences throughout the world and also given poster and oral presentation. He is also a life time member of Indian Pharmacy Graduate Association (IPGA). Has experience in the area of Pharmaceutics, nanoformulation based targeting, Bioanalysis, Pharmacokinetic, Biopharmaceutics and Pharmacodynamic studies, working mainly in: Medicinal plants, New Research Drugs and their development, UPLCMS/MS, NMR, FT-IR, Zetasizer, SEM, TEM and UPLC.

\section{REFERENCES}

1. Furr, BJ, Jordan VC. The pharmacology and clinical uses of tamoxifen. Pharmacol Ther. 1984;25(2):127-05.

2. Park WC, Jordan VC. Selective estrogen receptor modulators (SERMS) and their roles in breast cancer prevention. Trends Mol Med. 2002;8(2):82-8.

3. Yang J, Lu X, Pan L, Jiang K, Cheng M, Li F. Simultaneous enantio-separation of four beta 2-agonists by capillary electrophoresis with cyclodextrin additives. J Sep Sci. 2008:31(21):3749-54.

4. Huang L, Lin JM, Yu L, Xu L, Chen G. Improved simultaneous enantio-separation of beta-agonists in $\mathrm{CE}$ using beta-CD and ionic liquids. Electrophoresis. 2009;30(6):1030-36

5. Loden $\mathrm{H}$, Hedeland $Y$, Hedeland M, Bondesson U. Development of a chiral nonaqueous capillary electrophoretic system using the partial filling technique with UV and mass spectrometric detection. J Chromatogr A. 2003;986(1):143-52.

6. Kim KH, Kim DS, Hong SP, Keon OS. Reversed-phase high performance liquid chromatographic separation of the enanti-omers of terbutaline by derivatization with 2,3,4,6-tetra-o-acetyl-beta-d-glucopyranosyl isothiocyanate. Arch Pharm Res. 2000;23(1):26-30.

7. Bakhtiar R, Tse FL. High-throughput chiral liquid chromatography/tandem mass spectrometry. Rapid Commun Mass Spectrom. 2000;14(13):1128-35.

8. Ranjan OP, Nayak UY, Reddy MS, Dengale SJ, Musmade PB, Udupa N. Development and validation of RP-HPLC method with ultraviolet detection for estimation of montelukast in rabbit plasma: Application to preclinical pharmacokinetics. J Young Pharm. 2013;5(4):133-8.

9. Narapusetti A, Bethanabhatla SS, Sockalingam A, Pilli NR. LC-MS/MS assay for Acetazolamide, A Carbonic Anhydrase Inhibitor in Human Plasma and its Clini- cal Application. J Young Pharm. 2015;7(4):438-45.

10. Patel KM, Patel CN, Panigrahi B, Parikh AS, Patel HN. Development and Validation of Spectrophotometric Methods for the Estimation of Mesalamine in Table Dosage Forms. J Young Pharm. 2010;2(3):284-8.

11. Yang $L$, Wu N, Clement RP, Rudewicz PJ. Validation and application of a liquid chromatography tandem mass spectrometric method for the determination of $\mathrm{SCH} 211803$ in rat and monkey plasma using automated 96-well protein precipitation. J Chromatogr B. 2004;799(2):271-80

12. US Food and Drug Administration. Guidance for industry. Bioanalytical method validation; May 2001. http://www.fda.gov/cder/guidance/index.htm (accessed May 2012).

13. Lakhani NJ, Lepper ER, Sparreboom A, Dahul WL, Venitz J, Figg WD. Determination of 2-methoxyestradiol in human plasma, using liquid Chromatography/ tandem mass spectrometry. Rapid Commun Mass Spectrom. 2005;19(9):117682.

14. Guidance for Industry, Bioanalytical Method Validation, US Department of Health and Human Services Food and Drug Administration, Center for Drug Evaluation and Research (CDER), Center for Veterinary Medicine (CV), 2001 availableat:http://www.fda.gov/downloads/Drugs/GuidanceComplianceRegulatoryInformation/Guidance/UCM070107.pdf.

15. El-Kamel A, Al-Dosari H, Al-Jenoobi F. Environmentally Responsive Ophthalmic Gel Formulation of Carteolol Hydrochloride. Drug Deliv. 2006;13(1):55-9.

16. Katare YK, Muthukumaran T, Panda AK. Influence of particle size, antigen load dose and additional adjuvant on the immune response from antigen loaded PLA microparticles. Int J Pharm. 2005:301(1-2):149-60. 